\title{
Cryptosporidium Infection in Goats in Serbia
}

\author{
Ivan PAVLOVIĆ ${ }^{*}$, Snežana IVANOVIĆ ${ }^{1}$, Milan P.PETROVIĆ ${ }^{2}$, Violeta CARO-PETROVIĆ ${ }^{2}$, Dragana RUŽIĆ- \\ MUSLIĆ $^{2}$, Jovan BOJKOVSKI ${ }^{3}$, Nemanja ZDRAVKOVIĆ ${ }^{1}$ \\ ${ }^{1}$ Scientific Veterinary Institute of Serbia, 11000 Belgrade, Serbia \\ ${ }^{2}$ Institute for Animal Husbandry, 11000 Belgrade, Serbia \\ ${ }^{3}$ Faculty of Veterinary Medicine,University of Belgrade, 11000 Belgrade, Serbia \\ *Corresponding author: dripavlovic58@gmail.com
}

Bulletin UASVM Veterinary Medicine $77(2) / 2020$

Print ISSN 1843-5270; Electronic ISSN 1843-5378

doi:10.15835/buasvmcn-vm:2020.0027

\begin{abstract}
Cryptosporidiosis is an anthropozoonosis caused by coccidia of the family Cryptoporididae, whish may cause a serious health problem for kids in the first weeks of life. In our paper we presented results of examination of goat cryptosporidiosis in Serbia. In period 2016-2019 we examined 197 goat herds. Total of 1576 faecal smears were examined by Sheather's sugar floatation technique and modified Ziehl-Neelsen staining technique. Cryptosporidiosis were found at 119 herds. Kids between five and twenty-one days old are the most susceptible. The morbidity varies from $75-100 \%$ and the mortality from $45-50 \%$. Some animals do not develop into chronic cases and become carriers. After infection, animals either resist the organism, develop a mild infection that is self limiting, or soon sicken and die. Based on the performed research, we have established a significant role of cryptosporidiosis in the development of neonatal enteropathies of kids.
\end{abstract}

Keywords: Cryptosporidiosis, goats, kids, pathology

\section{Introduction}

Cryptosporidiosis is a zoonotic parasitic disease caused by Cryptosporidium spp. protozoan pathogen of the Phylum Apicomplexa. Cryptosporidiosis is typically an acute short-term infection. Cryptosporidiosis parasites are passed in the stool of infected animals and humans. Anyone can get cryptosporidiosis, but persons with weakened immune systems may develop serious, life-threatening illness (Fayer, 2004). Cryptosporidium oocysts can contaminate soil and the food grown in it. They can get onto objects and surfaces that people touch (Robertson, 2009, Ryan et al., 2014). They can get into lakes, rivers, streams, and pools where people swim. Sources of disease include parasite containing stool, food and water (Brandonisio, 2006, Delafosse et al., 2006, Giangaspero, 2006). Cryptosporidiosis in animals is most frequently recognized in pre- weaned farmed animals, younglings, and is an economically important disease. Clinical signs include diarrhoea, weight loss and anorexia (Smith, 1990; Soltane et al., 2007).

Currently, over 30 Cryptosporidium species have been recognized based on morphological, biological and molecular characteristics (Xiao et al., 2004; Ryan et al., 2014). At goats persist like coman species C.parvum, C. ubiquitum and C. xiaoi. Exept that species, at goats were occured infection with C. andersoni, C.bovic, C.fayeri, C.hominis (previously C. parvum genotype 1).C. canis, C. felis, C. meleagridis, C. ubiquitum and C. muris (Quilez et al., 2008; Chalmers and Goles, 2010). Goats cryptosporidiosis is mainly a disease of young kids of $0-2$ months old, the prepatent period is around 4 days and clinical symptoms are more prominent in younglings. In this age cryptosporidiosis had high morbidity and mortality rate (Bomfim et al., 
2005). Main symptoms of acute cryptosporidiosis include mild-to-moderate or severe diarrhoea, but other clinical symptoms may include depression, dehydration, anorexia, listlessness, unthriftiness and abdominal pain (DeGraaf et al., 1999). Consequence are significant increase of kid accrescense, its weakens and less develop (Foreyt, 1990; Olson et al., 1997). Goats cryptosporidiosis was first time established in Serbia during nineties years of the last century (Pavlović, 2008) and the first detailed studies of its prevalence followed in the period 2008-2009 by Pavlovic et al., (2010).

The aim of our paper is to present new knowledge about a prevalence of cryptosporidial infection in goats in Serbia in last five years.

\section{Materials and methods}

In period 2016-2019 we examined 197 goat herds from 19 villages from varius area in Serbia. Total of 1576 faecal smears were examined by Sheather's sugar floatation technique and stained modified Ziehl-Neelsen staining technique (Fayer et al., 1997). At same time total of 37 kids corpses are examined post mortem. After routine necropsy to parasitological examination we used faecal swab, gut contents and a mucous scrape of gut which we examined in direct smears stained by modified Ziehl-Neelsen technique. In addition section of jejunum, ileum and spiral colon from each kid were fixed in natural buffered 10\% formal in, embedded in paraffin, sectioned at 6 micrometer, stained with hematoxylin and eosin.
All samples were examined by use of the light microscopy.

\section{Results and discussions}

During our examination cryptosporidiosis was found at 119 herds (60.40\%). Determination of subspecies we not performed (Figure 1). Kids between five and twenty-one days were the most susceptible for infection. Once kids being infected, they excrete oocysts in their feces in about five days.

During our research, acute cryptosporidiosis was most often found in diseased kids. This symptoms include inapetence, weight loss, and diarrhea which is usually yellow to yellowishbrown and of a creamy texture (Pavlović et al., 2010). The rapid loss of nutrients and fluids during diarrhea results in dehydration (Mason et al., 1981). Since intestinal tract cells are disrupted, absorption of feed nutrients is restricted, and the animal loses more nutrients through the digestive tract and have lover feed conversion ratio. After infection, animals either resist the organism, develop a mild infection that is self limiting, or soon sicken and die (Mason et al., 1981; Thamsbrg et al., 1990a, Molina et al., 1994; Castro-Hermida, 2005).

If we compare these results with the research done in the period 2007-2008, we will notice that there was an increase in the prevalence of kid infection (Figure 2).

During post mortal examination cryptosporidial organisms were detected in the microvillus

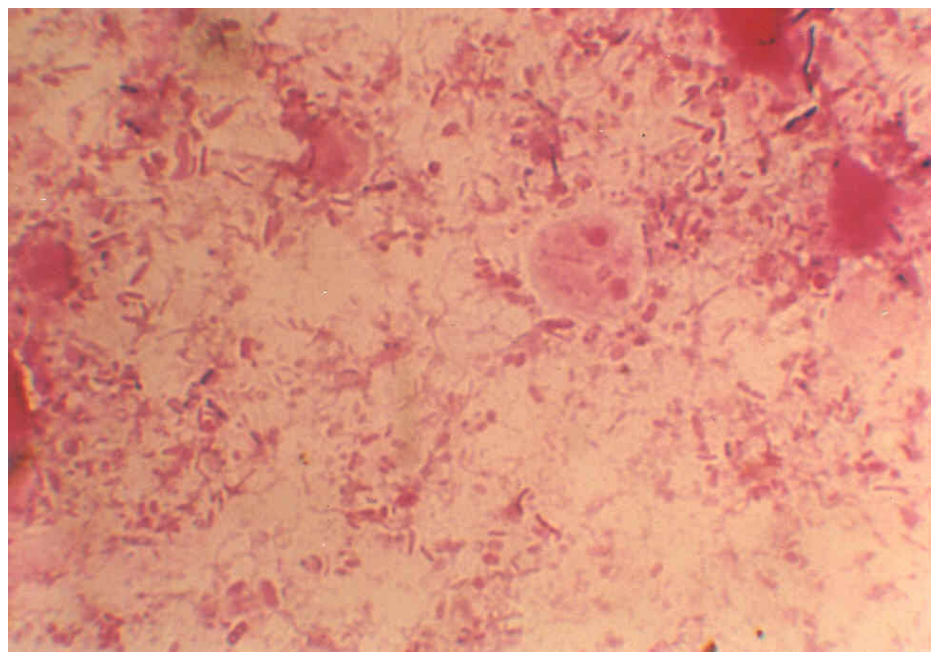

Figure 1. Oocyst of Cryptosporidium spp. 
brush border in the intestine. Macroscopical lesions include haemorhagical and catarrhal enteritis (De Graaf et al., 1999; Bomfim et al., 2005). Parasites were located extracytoplasmic, at parasitophorus vacuole, in intestinal mucosa primarily in the brush border of the ileum and especially in the dome epithelium covering the Payer's patches. When only a few organisms were detected they consistently could be found in dome epithelium. In the jejunum parasites always were located on the villous epithelium (Pavlović et al., 2008, 2009). In seven kids cryptosporidia were found in the ileum, jejunum and colon (Klein et al., 2008). At histological intestine section, when lesion is present, they consist of mild to moderate villous atrophy, especially over ileal domes, and invasion of the lamina propria by large numbers of the mononuclear inflammatory cells and fewer eosinophilis.

The extent to which a kid is infected seems to be dependent on its age and immune status. Younger animals are much more susceptible to infection than adults. During our examination sick kids were 4 days to 2 months old. At five-day-old kids had diarrhea for 9-10 days and suffered from a high rate of mortality. Sixty-day-old kids showed no symptoms when they were infected and adult goats completely resisted infection. Being a monoxenous parasite with direct life cycle, the cryptosporidial infection is transmitted through feco-oral route by the ingestion of oocysts through contaminated feed and fodder or drinking water (Goyena et al.1997).

Young animals account for the main source of environmental contamination. The infection subsides with attainment of immunological maturity; the recovered animals become a carrier, thereby serving as a potential source of infection to susceptible population (Njau et al., 1990; King and Monis, 2007). In the adults, the disease runs a chronic course characterized by progressive loss in body weight but most of the infected animals remain asymptomatic. Oocysts are fully sporulated when excreted. There are two types of oocysts - the thick walled oocysts and the thin walled oocysts (Mehlhorn, 1988). The thick walled oocysts excreted in faeces and are infective to other hosts whereas, the thin-walled oocysts burst while in intestine and the released sporozoites give rise to endogenous autoinfection which is a unique characteristic of Cryptosporidium spp. (Levine, 1984; Mehlhorn, 1988). The rate of excretion of oocysts depends upon the severity of infection as well as the age of the animal (Paraud and Chartier, 2011). However, adult animals also excrete oocysts in the environment but the magnitude varies. Transmission of the parasites is direct, either by the faeco-oral route or contamination of water supplies with the oocysts which are the infective stages of the parasite (Fayer, 2004).

During our examination, cryptosporidia was not determinate to be the only cause of diarrhea in examined kids. With few exceptions, cryptosporidia were associated with sub clinical infection. Even in the $32 \%$ of cryptosporidia infected kids with diarrhea, other enteric pathogens (E.coli, salmonellosis, campylobacteriosis, etc.) or lesions, independently capable of causing diarrhea (Munoz et al., 1996; Pavlović et al., 2010; Ivanović and Pavlović, 2017).

Evidence for the role of goats in human cryptosporidiosis has been questioned because only a few studies investigating about the infecting species. Although nonhuman pathogenic species,

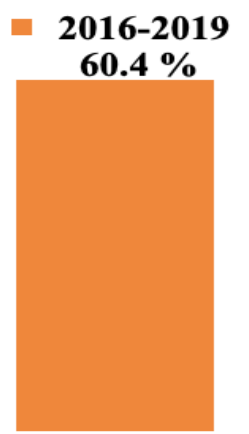

Figure 2. Comparative presentation of the prevalence of infection of kids with Cryptosporidium sp. 
including C. xiaoi may have been risk to human health, especially from goats infected with $C$. parvum, C. ubiquitum and C.hominis (previously $C$. parvum genotype 1) (Caccio et al., 2005; Giles et al., 2005).

\section{Conclusion}

Based on the performed research, we found that the prevalence of cryptosporidiosis in goats in Serbia is increasing. This coincides with the trend of increasing the number of goat herds in the last few years. Due to the health significance of goats and the zoonotic potential of cryptospores, in the following period it is necessary to perform a molecular analysis of the established parasites in order to obtain accurate data on the presence of certain species of cryptospores in goats.

Acknowledgments. This study was supported by the Ministry of Education, Science and Technological Development, Republic of Serbia (Contract for research funding No. 451-03-68/202014/200030) and its part of project BT 31053.

\section{References}

1. Bomfim TC, Huber F, Gomes RS, Alves LL (2005). Natural infection by Giardia sp. and Cryptosporidium sp. in dairy goats, associated with possible risk factors of the studied properties.Veterinary Parasitology, 134: 9-13.

2. Brandonisio O (2006). Waterborne transmission of Giardia and Cryptosporidium. Parassitologia, 48: 91-94.

3. Castro-Hermida JA, Delafosse A, Pors I, AresMazás E, Chartier C (2005). Giardia duodenalis and Cryptosporidium parvum infections in adult goats and their implications for neonatal kids..Veterinary Record, 157: 623-627.

4. Caccio SM, Thompson RCA, McLauchlin J, Smith HV (2005). Unravelling Cryptosporidium and Giardia epidemiology. Parasitology, 21: 430-437.

5. Chalmers RM, Goles M (2010). Zoonotic cryptosporidiosis in the UK - challenges for control. J Appl Microb. Doi:10.1111/j.1365-2672.2010.04764.x.

6. Delafosse A, Castro-Hermida Ja, Baudry C, AresMazás E, Chartier C (2006). Herd-level risk factors for Cryptosporidium infection in dairy-goat kids in western France.Preventive Veterinery Medicine, 77: 109-121.

7. De Graaf DC, Vanopdenbosch E, Ortega-Mora LM, Abbassi $\mathrm{H}$, Peeters JE (1999). A review of the importance of cryptosporidiosis in farm animals.International Journal of Parasitology, 29: 1269-1287.

8. Fayer R, Speer CA, Dubey JP (1997). The general biology of Cryptosporidium; In: Fayer R, Ed. Cryptosporidium and Cryptosporidiosis. Boca Raton: CRC Press, pp. 1-42.
9. Fayer R (2004). Cryptosporidium: a water-borne zoonotic parasite. Veterinary Parasitology, 126: 37-56.

10. Foreyt WJ (1990). Coccidiosis and cryptosporidiosis in sheep and goats.Veterinary Clinical North American Food and Animal Practice, 6: 655-670.

11. Giangaspero A (2006). Giardia, Cryptosporidium and the spectre of zoonosis: The Italian experience from land to sea.Parassitologia, 48: 95-100.

12. Goyena M, Ortiz JM, Alonso FD (1997). Influence of different systems of feeding in the appearance of cryptosporidiosis in goat kids. Journal of Parasitology, 83:1182-1185.

13. Giles M, Chalmers R, Pritchard G, Elwin K, Mueller-Doblies D, Clifton-Hadley F (2005). Cryptosporidium hominis in a goat and a sheep in the UK. Veterinary Record, 164:24-25.

14. Ivanović S, Pavlović I (2015). Meso koza - bezbedna namirnica. Beograd,: Naučni institut za veterinarstvo Srbije.

15. King BJ, Monis PT (2007). Critical processes affecting Cryptosporidium oocyst survival in the environment. Parasitology, 134: 309-323.

16. Klein P, Kleinova T, Volek Z, Simunek J (2008). Effect of Cryptosporidium parvum infection on the absorptive capacity and paracellular permeability of the small intestine in neonatal calves. Veterinary Parasitology 152: 53-59.

17. Levine ND (1984). Taxonomy and review of the coccidian genus Cryptosporidium. Journal of Protozoology, 131: 9498..

18. Mason RW, Hartley WJ, Tilt L (1981). Intestinal cryptosporidiosis in a kid goat. Australian Veterinary Journal, 57:386-388.

19. Molina JM, Rodríguez-Ponce E, Ferrer O, Gutiérrez AC, Hernández S (1994). Biopathological data of goat kids with cryptosporidiosis. Veterinary Record,135: 67-68.

20. Mehlhorn H (1988). Parasitology in Focus: facts and trends., Berlin, Heidelberg: Springer Verlag.

21. Munoz M, Alvarez M, Lanza I, Carmenes P (1996). Role of enteric pathogens in the aetiology of neonatal diarrhoea in lambs and goats kids in Spain. Epidemiology and Infection, 117: 203-211.

22. Njau BC, Scholtens RG, Kasali O (1990). Parasites of sheep at the international livestok centre for afrika debre berhan station, Ethiopia. Preventive Veterinary Medicine, 9(4): 267-277.

23. Olson ME, Thorlakson CL, Deselliers L, Morck DW, Mcallister TA (1997). Giardia and Cryptosporidium in Canadian farm animals.Veterinary Parasitology, 68: 375381.

24. Paraud C, Chartier C (2011) Cryptosporidiosis in small ruminants. Small Ruminant Research, 103(1): 93-97

25. Pavlović I (2008). Endoparaziti koza i ovaca - protozoarna obolenja Veterinarski informator, 30/31:63-64

26. Pavlović I, Ivanović S, Žujović M (2009). Coccidiosis of goats and its role and importance of goat production Proceeding of IV Balkan Conference of Animal Science BALNIMALCON 2009, Challenges of the Balkan Animal 
industry and the Role of science and Cooperation, Stara Zagora, Bulgaria, 393-395.

27. Pavlovic I, Ivanovic S, Žujovic M, Tomic, Z (2010). Goat criptosporidiosis and its importance at goat production pathology, Biotechnolgy in Animal Husbandry, 26:187192.

28. Quílez J, Torres E, Chalmers RM, Hadfield SJ, Del Cacho E, Sánchez-Acedo C (2008). Cryptosporidium genotypes and subtypes in lambs and goat kids in Spain. Applied Environmental Microbiology, 74: 6026-6031.

29. Robertson LJ (2009). Giardia and Cryptosporidium infections in sheep and goats: a review of the potential for transmission to humans via environmental contamination. Epidemiology and Infection, 137: 913-921.
30. Ryan U, Fayer R, Xiao L. Cryptosporidium species in humans and animals: current understanding and research needs. Parasitology. 2014;141:1667-85.

31. Smith MC (1990). Exclusion of infectious diseases from sheep and goat farms. Veterinary Clinics of North America Food Animal Practice, 6(3): 705-720.

32. Soltane R, Guyot K, Dei-Cas E, Ayadi A (2007). Prevalence of Cryptosporidium spp. (Eucoccidiorida: Cryptosporiidae) in seven species of farm animals in Tunisia..Parasitology, 14: 335-338.

33. Thamsborg SM, Jørgensen RJ, Henriksen SA (1990). Cryptosporidiosis in kids of dairy goats. Veterinary Record, 127: 380-381.

34. Xiao L, Fayer R, Ryan U, Upton SJ (2004). Cryptosporidium taxonomy: Recent advances and implications for public health. Clinical Microbiology Reviews,17: 72-97. 